\title{
Genetic Analysis of Host Species Specificity of Magnaporthe oryzae Isolates from Rice and Wheat
}

\author{
Y. Tosa, H. Tamba, K. Tanaka, and S. Mayama
}

Faculty of Agriculture, Graduate School of Science and Technology, Kobe University, Nada, Kobe 657-8501, Japan. Accepted for publication 23 December 2005.

\begin{abstract}
Tosa, Y., Tamba, H., Tanaka, K., and Mayama, S. 2006. Genetic analysis of host species specificity of Magnaporthe oryzae isolates from rice and wheat. Phytopathology 96:480-484.

A Triticum isolate (pathogenic on wheat) of Magnaporthe oryzae was crossed with an Oryza isolate (pathogenic on rice) to elucidate mechanisms of their parasitic specificity on wheat. When the pathogenicity of

ratio. This result suggests that three loci are involved in avirulence of the Oryza isolate on wheat. One of the three loci conditioned papilla formation, whereas the others conditioned the hypersensitive reaction. Allelism tests revealed that the locus conditioning papilla formation is $P w t 2$ while one of the two loci conditioning the hypersensitive reaction is $P w t 1$. The other locus conditioning the hypersensitive reaction was different from any other known loci and, therefore, was designated as $P w t 5$.
\end{abstract} their $\mathrm{F}_{1}$ cultures (hybrids between a Triticum isolate and an Oryza isolate) was tested on wheat, avirulent and virulent cultures segregated in a 7:1

Magnaporthe oryzae (1) (anamorph, Pyricularia oryzae) is a causal agent of blast disease on gramineous plants. This species is isolated mainly from staple crops such as rice (Oryza sativa), foxtail millet (Setaria italica), common millet (Panicum miliaceum), finger millet (Eleusine coracana), oat (Avena sativa), and wheat (Triticum aestivum). Isolates from each crop are almost exclusively pathogenic on their original host genus $(6,8)$. Kato et al. (6) called this specific parasitism plant species specificity in the blast system following the definition by Heath (3).

$M$. oryzae isolates with different host ranges are interfertile (6) and, therefore, are amenable to genetic analysis of the plant species specificity. Yaegashi (14) crossed Eleusine isolates with weeping lovegrass isolates, and suggested that their specific parasitism on finger millet or weeping lovegrass was conditioned by a single gene. Valent and her coworkers identified major genes controlling avirulence of an Eleusine isolate and an Oryza isolate on weeping lovegrass, and designated them as $P W L 1$ and $P W L 2$, respectively (13). The cloned $P W L 1$ and $P W L 2$ genes resembled classical avirulence genes in that they were highly specific and dominant $(4,9)$. However, weeping lovegrass is a weed that exhibits complicated specificity with $M$. oryzae isolates. For example, it is resistant to some isolates from Oryza, Setaria, and Eleusine and susceptible to other isolates from these three plant genera (6). Genetic mechanisms of plant species specificity on staple crops have not been elucidated.

Our laboratory has performed "pivot turn crossing" for genetic analyses of the plant species specificity $(7,10)$. We chose a Triticum isolate $(\mathrm{Br} 48)$ as the pivot because it is highly fertile with other isolates of M. oryzae (unpublished data). Murakami et al. (7) crossed the Triticum isolate with a Setaria isolate (GFSI17-2) and produced $80 F_{1}$ cultures. Segregation analyses of the $F_{1}$ cultures showed that avirulence of the Setaria isolate on wheat is governed by two loci, Pwtl and Pwt2. Pwt1, associated with the lesion color, primarily conditioned the hypersensitive reaction at the cytological level. whereas Pwt2, associated with the lesion

Corresponding author: Y. Tosa; E-mail address: tosayuki@kobe-u.ac.jp

DOI: 10.1094/PHYTO-96-0480

(C) 2006 The American Phytopathological Society
Additional keyword: Pyricularia.

number, primarily conditioned papilla formation (7). Subsequently, Takabayashi et al. (10) crossed the Triticum isolate with an Avena isolate $(\mathrm{Br} 58)$ and produced $88 \mathrm{~F}_{1}$ cultures. Segregation analyses of the $\mathrm{F}_{1}$ cultures showed that avirulence of the Avena isolate on wheat is governed by two other loci, Pwt3 and Pwt4. The avirulence and virulence alleles at those four loci were designated as PWT1 and pwt1, PWT2 and pwt2, PWT3 and pwt3, and PWT4 and $p w t 4$, respectively (10).

The most familiar and economically important isolates of $M$. oryzae are those from Oryza spp. In the present study, we crossed the Triticum isolates with an Oryza isolate from Indonesia and performed genetic analyses to elucidate mechanisms of avirulence of Oryza isolates on wheat.

\section{MATERIALS AND METHODS}

Fungal strains and genetic crosses. Parental field isolates were M. oryzae $\mathrm{Br} 48$ (MAT1-1) isolated from wheat in Brazil and PO12-7301-2 (MAT1-2) (5) isolated from rice in Indonesia. Br48 was virulent on wheat and avirulent on rice, whereas PO12-73012 was virulent on rice and avirulent on wheat. They were crossed on an oatmeal agar medium (20 g of oatmeal, $10 \mathrm{~g}$ of agar, and $2.5 \mathrm{~g}$ of sucrose in $500 \mathrm{ml}$ of water) in a petri dish as described previously (7). The resulting $F_{1}$ ascospores were isolated from asci as described previously (7) and established as hybrids between a Triticum isolate and an Oryza isolate (TO cultures). For allelism tests, some of the TO cultures were crossed with $3 \mathrm{~K} 1$, $3 \mathrm{M} 1$, 61M2, or 86Q1, hybrid cultures with known genotypes. Cultures 3K1 (pwt1; PWT2) and 3M1 (PWT1; pwt2) were $\mathrm{F}_{1}$ cultures derived from the cross between Br48 and GFSI1-7-2 (an isolate from foxtail millet collected in Japan) (7), and tentatively were designated as hybrids between a Triticum isolate and a Setaria isolate (TS cultures). Cultures 61M2 (pwt3;PWT4) and 86Q1 (PWT3;PWT4) were $\mathrm{F}_{1}$ cultures derived from the cross between $\mathrm{Br} 48$ and $\mathrm{Br} 58$ (an isolate from oat collected in Brazil) (10), and tentatively were designated as hybrids between a Triticum isolate and an Avena isolate (TA cultures).

Plant material and infection assay. T. aestivum cv. Norin 4 was used as a test plant. Twelve seeds were sown in vermiculite in a seedling case of 5.5 by 15 by $10 \mathrm{~cm}$, and grown at 22 to $23^{\circ} \mathrm{C}$ in 
a controlled-environment room with a 12-h photoperiod of fluorescent lighting for 7 to 9 days. Sporulation of $M$. oryzae cultures to be tested was induced as described previously (7). The conidia produced were suspended in water and adjusted to a concentration of $3 \times 10^{5}$ spores $/ \mathrm{ml}$ with $0.01 \%$ Tween 20 . The conidial suspension $(10 \mathrm{ml} /$ seedling case) was sprayed on the adaxial surface of wheat leaves with an air compressor. The inoculated seedlings were kept in a humid, dark box for 20 to $24 \mathrm{~h}$ at 22 to $23^{\circ} \mathrm{C}$. They then were transferred to the controlled-environment room mentioned above and incubated further at 22 to $23^{\circ} \mathrm{C}$. Five days after inoculation, symptoms were evaluated based on the color and number of lesions. The pathogenicity test was repeated at least three times.

Microscopic observation. The inoculated leaves were fixed in alcoholic lactophenol $48 \mathrm{~h}$ after inoculation and observed with a fluorescence microscope as described previously (7). A total of 200 appressoria on two leaves were counted for each culture. This experiment was repeated three times. The incidence of cellular responses was subjected to arcsine transformation and compared by a $t$ test.

\section{RESULTS}

Production of $F_{1}$ cultures between Br48 and PO12-7301-2. From the cross of the Triticum isolate $\mathrm{Br} 48$ with the Oryza isolate PO12-7301-2, a total of $111 \mathrm{~F}_{1}$ cultures was obtained. These cultures were derived from 13 mature asci with 8 ascospores and 1 ascus with 7 ascospores. Ascus numbers from 41 through 54 were assigned to these 14 asci. A mature ascus of $M$. oryzae should contain four pairs of sister progenies. All the pairs could be determined easily by the appearance of their mycelial colonies on artificial media. The four pairs were designated by letters K, L, M, and $\mathrm{N}$. By combining the ascus numbers and the letters, the $\mathrm{F}_{1}$ cultures were designated as $41 \mathrm{~K} 1,41 \mathrm{~K} 2,41 \mathrm{~L} 1,41 \mathrm{~L} 2,41 \mathrm{M} 1$, $41 \mathrm{M} 2,41 \mathrm{~N} 1,41 \mathrm{~N} 2$, and so on. Here, cultures with the same letter (e.g., $41 \mathrm{~K} 1$ and $41 \mathrm{~K} 2$ ) are sister progenies of a pair.

Genetic analysis of pathogenicity of the $F_{1}$ cultures on wheat. Murakami et al. (7) found four lesion types on wheat leaves incubated at $25^{\circ} \mathrm{C}$ after inoculation: $\mathrm{B}-$, discrete brown pinpoint lesions; $\mathrm{B}+$, confluent brown lesions; $\mathrm{G}-$, discrete green lesions; and $\mathrm{G}+$, confluent green lesions. When the inoculated leaves were incubated at $20^{\circ} \mathrm{C}$, the $\mathrm{B}-, \mathrm{B}+$, and $\mathrm{G}-$ types turned to a completely avirulent phenotype, whereas the G+ type remained a virulent phenotype (10). These results suggested that the $\mathrm{B}+$ and $\mathrm{G}-$ types are attenuated phenotypes of avirulence caused by the increased temperature (10). Consequently, avirulence and virulence were discriminated more clearly at 20 than at $25^{\circ} \mathrm{C}$. However, the $\mathrm{B}+$ and $\mathrm{G}-$ phenotypes give us useful information because they are associated with different cellular reactions (hypersensitive reaction and papilla formation, respectively) and different genes ( $P W T 1$ and $P W T 2$, respectively) (7). In the inoculation test at $25^{\circ} \mathrm{C}$, the two types of genes can be discriminated by phenotypes. On the other hand, the four types of reactions are sometimes unstable at $25^{\circ} \mathrm{C}$ because this temperature is the upper limit for expressing the resistant responses. When the inoculated leaves were incubated at more than $25^{\circ} \mathrm{C}$, the $\mathrm{B}+$ and $\mathrm{G}-$ types became indistinguishable from the $\mathrm{G}+$ type. In the present study, therefore, we chose an intermediate temperature, 22 to $23^{\circ} \mathrm{C}$, for the incubation of inoculated leaves.

Wheat cv. Norin 4 was inoculated with the parental field isolates, $\mathrm{Br} 48$ and PO12-7301-2, and incubated at 22 to $23^{\circ} \mathrm{C}$. $\mathrm{Br} 48$ produced many water-soaked, green-to-pale green lesions by 3 days after inoculation. These lesions enlarged and coalesced with time, resulting in the shriveling of the whole leaf by 5 days after inoculation (Fig. 1). This phenotype corresponded to the typical G+ lesion. In contrast, PO12-7301-2 produced a few brown spots without visible centers (Fig. 1). This phenotype corresponded to the typical B- lesion. When Norin 4 was inoculated with the 111 TO cultures derived from the cross between $\mathrm{Br} 48$ and PO12-7301-2, various degrees and types of infection were observed. The TO cultures included 17 cultures that induced no visible reactions on the wheat leaves. Preliminary cytological observation revealed that they had lost the basic capacity of penetration. These 17 cultures were excluded from further analysis. Phenotypes produced by the remaining 94 cultures were classified into the four types (i.e., B-, B+, G-, and G+) (Fig. 1). The B+type reactions observed in the present study were determined easily as an avirulent phenotype due to the lower temperature during the incubation than that adopted by Murakami et al. (7) (Fig. 1). Similarly, the Gtype observed in the present study was discriminated easily from the $\mathrm{G}+$ type and determined as an avirulent phenotype (Fig. 1).

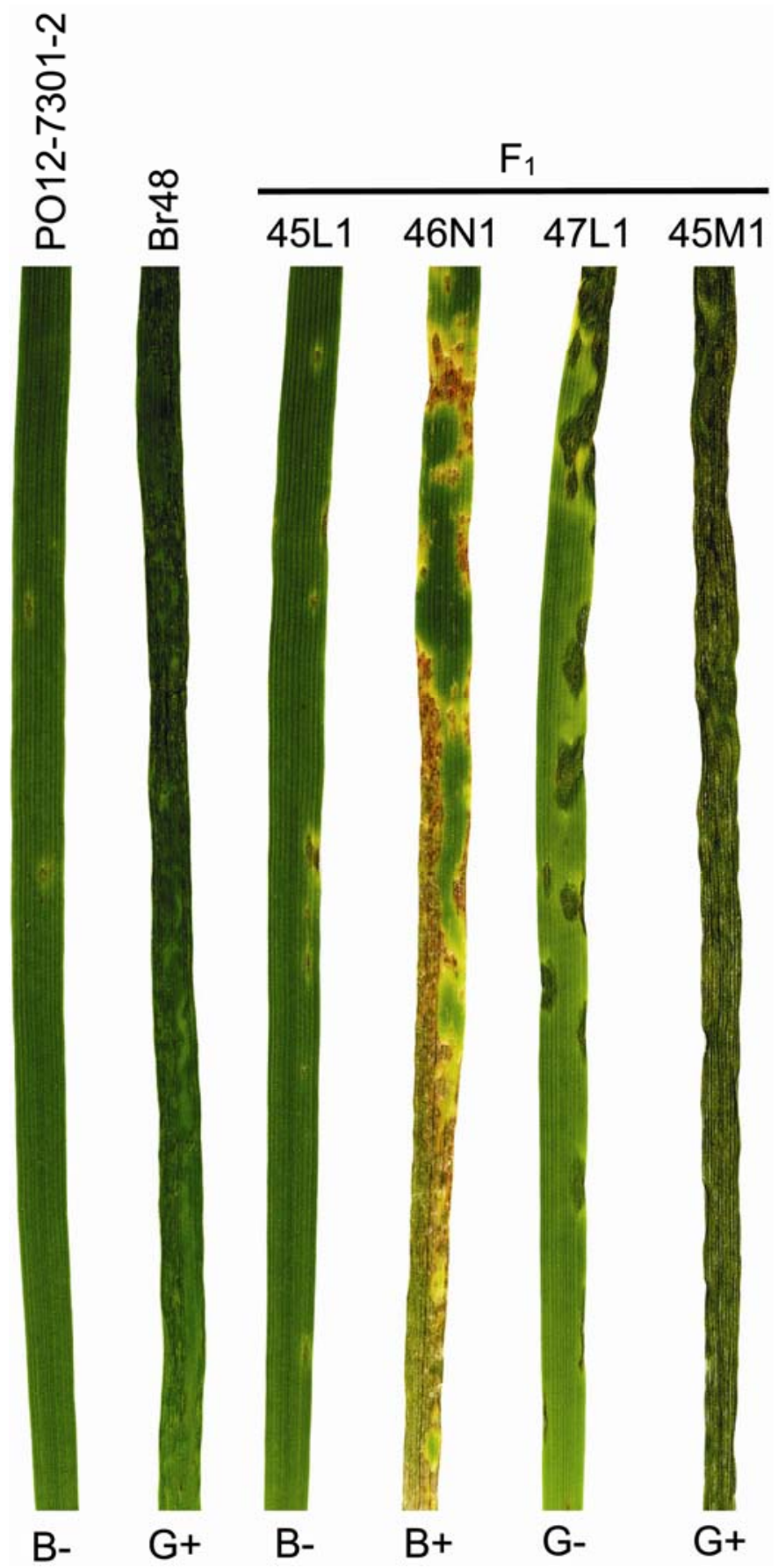

Fig. 1. Four lesion types on wheat cv. Norin 4 infected with Magnaporthe oryzae isolates PO12-7301-2, Br48, and their $\mathrm{F}_{1}(45 \mathrm{~L} 1,46 \mathrm{~N} 1,47 \mathrm{~L} 1$, and $45 \mathrm{M} 1), 5$ days after inoculation. B-, discrete brown lesions; B+, confluent brown lesions; $\mathrm{G}-$, discrete green lesions; $\mathrm{G}+$, confluent green lesions. 
The avirulent (B-, B+, and $\mathrm{G}-$ ) and virulent $(\mathrm{G}+)$ cultures segregated in a 7:1 ratio (Table 1), suggesting that three loci are involved in avirulence of PO12-7301-2 on Norin 4. The segregation of the brown types ( $\mathrm{B}-$ and $\mathrm{B}+$ ) and the green types $(\mathrm{G}-$ and $\mathrm{G}+$ ) fit a 3:1 ratio (Table 1), suggesting that the lesion color is associated with two of the three loci. The avirulence and virulence alleles at these two loci were tentatively designated as $A 1$ and $a 1$, and $A 2$ and $a 2$, respectively. The segregation of the discrete types (B- and $\mathrm{G}-$ ) and the confluent types (B+ and $\mathrm{G}+$ ) fit a 1:1 ratio (Table 1), suggesting that the lesion number is associated with the remaining one locus. The avirulence and virulence alleles at this locus tentatively were designated as $B 1$ and $b 1$. Finally, the segregation of the four lesion types fit a
3:3:1:1 ratio (Table 1 ), indicating that these three loci segregate independently.

Cytological responses associated with the three loci. To elucidate cellular responses conditioned by $A 1, A 2$, and $B 1$, inoculated leaves were fixed $48 \mathrm{~h}$ after inoculation and observed under a fluorescence microscope. Cytological responses were categorized into four types, A, B, C, and D, as reported previously (7), where $\mathrm{A}=$ no reaction of leaf cells, $\mathrm{B}=$ the formation of a papilla with yellow fluorescence, $\mathrm{C}=$ the hypersensitive reaction of an epidermal cell accompanied by strong yellow fluorescence, and D = the development of infection hyphae with no resistance reactions.

The avirulent parent PO12-7301-2 induced papilla formation in a high percentage (74\%) of appressorial penetration sites (Table 2).

TABLE 1. Segregation of lesion types on wheat cv. Norin 4 in $\mathrm{F}_{1}$ cultures derives from the cross between Magnaporthe oryzae isolates, Br48 and PO12-7301-2

\begin{tabular}{|c|c|c|c|c|c|c|c|c|}
\hline \multicolumn{5}{|c|}{ Number of $F_{1}$ cultures $^{a}$} & \multicolumn{4}{|c|}{$\chi^{2}$ for $^{b}$} \\
\hline B- & $\mathrm{B}+$ & $\mathrm{G}-$ & $\mathrm{G}+$ & Total & $1: 1$ & $3: 1$ & $7: 1$ & $3: 3: 1: 1$ \\
\hline \multirow[t]{4}{*}{36} & 38 & 10 & 10 & 94 & $\cdots$ & $\cdots$ & $\ldots$ & 0.75 \\
\hline & & & & 94 & $31.0 * *$ & 0.70 & $6.62 *$ & $\cdots$ \\
\hline & & & & 94 & 0.04 & $34.06^{* * *}$ & $\cdots$ & $\ldots$ \\
\hline & 84 & & 10 & 94 & $\ldots$ & $10.34 * *$ & 0.30 & $\ldots$ \\
\hline
\end{tabular}

a $\mathrm{B}-$, discrete brown lesions; $\mathrm{B}+$, confluent brown lesions; $\mathrm{G}-$, discrete green lesions; $\mathrm{G}+$, confluent green lesions.

b Significant at the $5 \%(*)$ and $1 \%(* *)$ levels.

TABLE 2. Cellular responses of wheat primary leaves (cv. Norin 4) to Magnaporthe oryzae isolates Br48 and PO12-7301-2 and their $\mathrm{F}_{1}$ cultures

\begin{tabular}{|c|c|c|c|c|c|c|}
\hline \multirow[b]{2}{*}{ Culture } & \multirow[b]{2}{*}{ Lesion type $^{\mathrm{a}}$} & \multicolumn{4}{|c|}{ Percentage of germlings inducing ${ }^{b}$} & \multirow[b]{2}{*}{ HR ratio $\mathrm{C} /(\mathrm{C}+\mathrm{D})^{\mathrm{c}}$} \\
\hline & & No reaction $(\mathrm{A})$ & Papilla formation $(\mathrm{B})^{\mathrm{c}}$ & $\operatorname{HR}(C)^{d}$ & Hyphal growth (D) & \\
\hline \multicolumn{7}{|l|}{ Parents } \\
\hline PO12-7301-2 & B- & 20.2 & 74.0 & 5.8 & 0.0 & 100.0 \\
\hline $\mathrm{Br} 48$ & G+ & 15.2 & 10.9 & 30.6 & 43.3 & 41.4 \\
\hline \multicolumn{7}{|l|}{$\mathrm{F}_{1}$ cultures } \\
\hline $43 \mathrm{~K} 1$ & $\mathrm{~B}-$ & 7.3 & 58.4 & 26.2 & 8.1 & 76.5 \\
\hline 43L1 & $\mathrm{B}-$ & 18.5 & 76.3 & 5.2 & 0.0 & 100.0 \\
\hline $45 \mathrm{~L} 1$ & B- & 5.1 & 94.5 & 0.4 & 0.0 & 100.0 \\
\hline $46 \mathrm{~K} 1$ & B- & 7.2 & 85.3 & 7.5 & 0.0 & 100.0 \\
\hline $47 \mathrm{~K} 1$ & B- & 26.7 & 71.3 & 2.0 & 0.0 & 100.0 \\
\hline 48L1 & B- & 23.7 & 70.0 & 6.3 & 0.0 & 100.0 \\
\hline 48M1 & B- & 9.8 & 83.3 & 6.9 & 0.0 & 100.0 \\
\hline $49 \mathrm{M} 2$ & B- & 3.8 & 92.9 & 3.3 & 0.0 & 100.0 \\
\hline 51L1 & B- & 24.2 & 72.1 & 3.7 & 0.0 & 100.0 \\
\hline $51 \mathrm{~N} 1$ & B- & 3.0 & 87.4 & 8.8 & 0.8 & 92.0 \\
\hline $54 \mathrm{M} 1$ & B- & 1.9 & 54.9 & 39.3 & 3.9 & 91.1 \\
\hline $43 \mathrm{~N} 2$ & $\mathrm{~B}+$ & 15.0 & 19.2 & 60.3 & 5.5 & 91.7 \\
\hline $45 \mathrm{~N} 1$ & $\mathrm{~B}+$ & 6.7 & 12.4 & 80.2 & 0.7 & 99.1 \\
\hline $46 \mathrm{~N} 1$ & $\mathrm{~B}+$ & 2.9 & 10.1 & 86.0 & 1.0 & 98.8 \\
\hline $47 \mathrm{M} 2$ & $\mathrm{~B}+$ & 1.7 & 14.4 & 83.9 & 0.0 & 100.0 \\
\hline $47 \mathrm{~N} 2$ & $\mathrm{~B}+$ & 14.6 & 7.6 & 55.6 & 22.2 & 71.4 \\
\hline $48 \mathrm{~K} 1$ & $\mathrm{~B}+$ & 9.8 & 18.8 & 66.9 & 4.5 & 93.7 \\
\hline 49L2 & $\mathrm{B}+$ & 1.4 & 14.5 & 83.1 & 1.0 & 98.8 \\
\hline $49 \mathrm{~N} 2$ & $\mathrm{~B}+$ & 1.9 & 12.5 & 85.6 & 0.0 & 100.0 \\
\hline $51 \mathrm{~K} 1$ & $\mathrm{~B}+$ & 3.1 & 21.9 & 70.5 & 4.5 & 94.1 \\
\hline $51 \mathrm{M} 1$ & $\mathrm{~B}+$ & 2.9 & 20.2 & 75.7 & 1.2 & 98.4 \\
\hline $54 \mathrm{~K} 1$ & $\mathrm{~B}+$ & 2.0 & 8.8 & 87.2 & 2.0 & 97.7 \\
\hline $54 \mathrm{~L} 1$ & $\mathrm{~B}+$ & 6.1 & 14.9 & 68.8 & 10.2 & 87.1 \\
\hline $45 \mathrm{~K} 1$ & G- & 16.2 & 79.2 & 1.8 & 2.8 & 38.5 \\
\hline $46 \mathrm{M} 2$ & G- & 2.9 & 94.7 & 0.8 & 1.6 & 33.3 \\
\hline $47 \mathrm{~L} 1$ & G- & 15.9 & 74.4 & 2.4 & 7.3 & 25.0 \\
\hline $49 \mathrm{~K} 2$ & G- & 4.8 & 90.9 & 0.7 & 3.6 & 16.7 \\
\hline $54 \mathrm{~N} 1$ & G- & 9.4 & 83.7 & 1.0 & 5.9 & 14.3 \\
\hline 43M1 & G+ & 5.2 & 11.9 & 11.9 & 71.0 & 14.4 \\
\hline $45 \mathrm{M} 1$ & $\mathrm{G}+$ & 33.8 & 19.9 & 31.6 & 14.7 & 68.3 \\
\hline 46L1 & G+ & 49.5 & 13.1 & 25.3 & 12.1 & 67.6 \\
\hline $48 \mathrm{~N} 2$ & $\mathrm{G}+$ & 46.3 & 11.8 & 3.2 & 38.7 & 7.7 \\
\hline
\end{tabular}

a B-, discrete brown lesions; B+, confluent brown lesions; G-, discrete green lesions; G+, confluent green lesions.

b Average of three replications.

c Significantly high values are enclosed (Table 3).

${ }^{\mathrm{d}} \mathrm{HR}=$ hypersensitive reaction. 
Although 5.8\% of germlings were not stopped at the papilla stage, they subsequently induced the hypersensitive reaction (HR) and failed to colonize wheat leaves. The HR ratio $(\mathrm{C} /[\mathrm{C}+\mathrm{D}])$ was $100 \%$. However, in wheat leaves inoculated with the virulent parent $\mathrm{Br} 48$, the incidence of papilla formation and the HR ratio were much lower (10.9 and $41.4 \%$, respectively). Consequently, almost half $(43.3 \%)$ of the germlings successfully colonized epidermal cells.

TABLE 3. Statistical analysis of relationships between lesion types and cellular responses

\begin{tabular}{lcccccc}
\hline & & \multicolumn{2}{c}{ Papilla formation $(\%)^{\mathrm{c}}$} & & \multicolumn{2}{c}{ HR ratio $^{\mathrm{c}}$} \\
\cline { 3 - 4 } \cline { 5 - 6 } Lesion type $^{\mathrm{a}}$ & No. tested $^{\mathrm{b}}$ & Average & $t$ value $^{\mathrm{d}}$ & & Average & $t$ value $^{\mathrm{d}}$ \\
\hline B- and B+ & 23 & 44.4 & 0.44 & & 95.2 & $9.11^{* *}$ \\
G- and G+ & 9 & 53.3 & $\ldots$ & & 31.8 & $\ldots$ \\
B- and G- & 16 & 79.3 & $13.03^{* *}$ & & 74.2 & 0.09 \\
B+ and G+ & 16 & 14.5 & $\ldots$ & 80.6 & $\ldots$ \\
\hline
\end{tabular}

${ }^{\mathrm{a}} \mathrm{B}-$, discrete brown lesions; $\mathrm{B}+$, confluent brown lesions; $\mathrm{G}-$, discrete green lesions; $\mathrm{G}+$, confluent green lesions.

${ }^{b}$ Number of $F_{1}$ cultures tested.

${ }^{\mathrm{c}}$ Refer to Table 2.

${ }^{\mathrm{d}}$ Results of $t$ test for group of two; ** indicates significant at the $1 \%$ level.

TABLE 4. Presumed genotypes of $F_{1}$ cultures derived from the cross between Magnaporthe oryzae isolates $\mathrm{Br} 48$ and PO12-7301-2

\begin{tabular}{lcccc}
\hline & & \multicolumn{3}{c}{ Genotype $^{\mathrm{b}}$} \\
\cline { 3 - 5 } Ascus no., F culture & Lesion type $^{\mathrm{a}}$ & $A l^{\mathrm{c}}$ & $A 2$ & $B 1$ \\
\hline 43 & & & & \\
K1, K2 & B- & ND & ND & + \\
L1, L2 & B- & ND & ND & + \\
M1, M2 & G+ & - & - & - \\
N1, N2 & B+ & ND & ND & - \\
45 & & & & \\
K1, K2 & G- & - & - & + \\
L1, L2 & B- & + & + & + \\
M1, M2 & G+ & - & - & - \\
N1, N2 & B+ & + & + & - \\
\hline
\end{tabular}

${ }^{\mathrm{a}} \mathrm{B}-$, discrete brown lesions; $\mathrm{B}+$, confluent brown lesions; $\mathrm{G}-$, discrete green lesions; $\mathrm{G}+$, confluent green lesions.

${ }^{\mathrm{b}} \mathrm{ND}$, not determined; +, avirulence allele; - , virulence allele.

${ }^{c}$ Locus.
In the $\mathrm{F}_{1}$ cultures (TO cultures), the incidence of these resistance reactions was closely related with the lesion types (Table 2). A $t$ test showed that the brown and green types were significantly different in the HR ratio, whereas the discrete and confluent types were significantly different in the incidence of papilla formation (Table 3). Consequently, the B- type was characterized by high incidences of papilla formation and high HR ratios (Table 2). The $\mathrm{B}+$ type was characterized by low incidences of papilla formation and high HR ratios, whereas the G- type was characterized by high incidences of papilla formation and low HR ratios. Only when both incidences were low did the infection result in the virulence phenotype, $\mathrm{G}+$ (Table 2). Based on these results, $A 1$ and $A 2$ determine lesion color by conditioning the HR, similar to $P W T 1$, and $B 1$ determines lesion number by conditioning papilla formation, similar to PWT2.

Allelism tests. In many sets of the TO cultures, it was not possible to infer precise genotypes from their phenotypes. An example of such sets is shown in Table 4. Set 43 is composed of three brown types $(\mathrm{K}, \mathrm{L}$, and $\mathrm{N})$ and one green type $(\mathrm{M}) . A 1$ and A2 should be present in two of the three brown types; in other words, one of $\mathrm{K}, \mathrm{L}$, and $\mathrm{N}$ should carry both $A 1$ and $A 2$ while the other two should carry either $A 1$ or $A 2$. It cannot be determined which is the carrier of both genes. From the viewpoint of lesion number, however, this set is composed of two discrete types ( $\mathrm{K}$ and $\mathrm{L}$ ) and two confluent types ( $\mathrm{M}$ and $\mathrm{N})$; therefore, $B 1$ should be present in $\mathrm{K}$ and $\mathrm{L}$. To determine whether the newly identified three avirulence genes include $P W T 2,43 \mathrm{~L} 1$ was crossed with $3 \mathrm{~K} 1$, a TS culture with genotype pwt $1 ; P W T 2$. Culture 43L1 should carry two genes $(A 1$ or $A 2, B 1)$ or three genes $(A 1, A 2$, and $B 1$ ), whereas $3 \mathrm{~K} 1$ carries a single gene, $P W T 2$. Let's assume that $A 1, A 2$, and $B 1$ are different from $P W T 2$. If $43 \mathrm{~L} 1$ carries the three genes, a total of four genes $(A 1, A 2, B 1$, and $P W T 2)$ should be involved in the progeny population and, therefore, avirulent and virulent cultures should segregate in a 15:1 ratio. If 43L1 carries the two genes, a total of three genes ( $A 1$ or $A 2, B 1$, and $P W T 2$ ) should be involved in the progeny population and, therefore, avirulent and virulent cultures should segregate in a $7: 1$ ratio. In fact, all 80 progeny cultures derived from this cross were avirulent on Norin 4 (Table 5). The ratio of avirulent and virulent cultures (80:0) was significantly different from $7: 1$ or $15: 1$. These results suggest that 43L1 carries $P W T 2$. In other words, one of $A 1$, $A 2$, or $B 1$ is $P W T 2$. As described above, $A 1$ and $A 2$ condition the HR while $B 1$ conditions papilla formation. Therefore, $P W T 2$ in

TABLE 5. Segregation of virulence on wheat cv. Norin 4 in progenies derived from crosses between Magnaporthe oryzae $\mathrm{F}_{1}$ cultures

\begin{tabular}{|c|c|c|c|c|c|c|c|c|c|c|c|c|c|c|}
\hline \multicolumn{3}{|c|}{ Parent $\mathrm{A}^{\mathrm{a}}$} & \multicolumn{3}{|c|}{ Parent $\mathrm{B}^{\mathrm{b}}$} & \multicolumn{6}{|c|}{ Number of progeny from $\mathrm{A} \times \mathrm{B}$} & \multirow[b]{2}{*}{ Ratio $^{\mathrm{d}}$} & \multirow[b]{2}{*}{$\chi^{2}$} & \multirow[b]{2}{*}{$P$} \\
\hline Name & Genotype & Lesion $^{\mathrm{c}}$ & Name & Genotype & Lesion $^{\mathrm{c}}$ & $\mathrm{B}-$ & $\mathrm{B}+$ & G- & G+ & Total & $(\mathrm{B}-, \mathrm{B}+, \mathrm{G}-): \mathrm{G}+$ & & & \\
\hline $43 \mathrm{~L} 1$ & $? ; ? ; B 1$ & B- & $3 \mathrm{~K} 1$ & $p w t 1 ; P W T 2$ & G- & 44 & 0 & 36 & 0 & 80 & $80: 0$ & $\begin{array}{r}7: 1 \\
15: 1\end{array}$ & $\begin{array}{r}11.42 \\
5.33\end{array}$ & $\begin{array}{l}<0.01 \\
0.01-0.05\end{array}$ \\
\hline $45 \mathrm{~N} 1$ & $A 1 ; A 2 ; b 1$ & $\mathrm{~B}+$ & $3 \mathrm{M} 1$ & $P W T 1 ; p w t 2$ & $\mathrm{~B}+$ & 0 & 60 & 0 & 0 & 60 & 60:0 & $7: 1$ & 8.57 & $<0.01$ \\
\hline $45 \mathrm{~N} 1$ & $A 1 ; A 2 ; b 1$ & $\mathrm{~B}+$ & $61 \mathrm{M} 2$ & $p w t 3 ; P W T 4$ & B- & 35 & 34 & 0 & 11 & 80 & 69:11 & $7: 1$ & 0.11 & $0.50-0.90$ \\
\hline $45 \mathrm{~N} 1$ & $A 1 ; A 2 ; b 1$ & $\mathrm{~B}+$ & $86 \mathrm{Q} 1$ & PWT3;PWT4 & B- & 46 & 21 & 0 & 7 & 74 & $67: 7$ & $15: 1$ & 1.30 & $0.10-0.50$ \\
\hline
\end{tabular}

${ }^{\mathrm{a}} \mathrm{F}_{1}$ derived from the cross, $\mathrm{Br} 48$ (Triticum isolate) $\times$ PO12-7301-2 (Oryza isolate).

b $3 \mathrm{~K} 1$ and $3 \mathrm{M} 1, \mathrm{~F}_{1}$ derived from the cross, $\mathrm{Br} 48 \times \mathrm{GFSI} 1-7-2$ (Setaria isolate); 61M2 and 86Q1, $\mathrm{F}_{1}$ derived from the cross, $\mathrm{Br} 48 \times \mathrm{Br} 58$ (Avena isolate).

${ }^{\mathrm{c}}$ Lesion type: $\mathrm{B}-$, discrete brown lesions; $\mathrm{B}+$, confluent brown lesions; $\mathrm{G}-$, discrete green lesions; $\mathrm{G}+$, confluent green lesions.

${ }^{\mathrm{d}}$ Expected ratio.

TABLE 6. Genotypes of Magnaporthe oryzae field isolates with host species-specific parasitism

\begin{tabular}{llccccc}
\hline & & \multicolumn{5}{c}{ Allele $^{\mathrm{a}}$} \\
\cline { 3 - 6 } Isolates & Original host & $P w t 1^{\mathrm{b}}$ & $P w t 2$ & $P w t 3$ & $P w t 4$ & - \\
\hline PO12-7301-2 & Oryza sativa & + & + & - & - & + \\
GFS11-7-2 & Setaria italica & + & + & - & - \\
Br58 & Avena sativa & - & - & - & - & - \\
Br48 & Triticum aestivum & - & - & - & - \\
\hline
\end{tabular}

a Avirulence (+) and virulence (-) alleles.

b Locus. 
43L1 should be $B 1$. The 80 progeny cultures showed the discrete types without exception, but contained the brown type (B-) and the green type $(\mathrm{G}-)$ in a 1:1 ratio (Table 5). This result suggests that 43L1 carries only one gene for the brown phenotype.

In some sets, genotypes of all four cultures could be determined from phenotypes. Set 45 contained all four phenotypes: $\mathrm{B}-, \mathrm{B}+$, $\mathrm{G}-$, and $\mathrm{G}+$ (Table 4). In this case, the brown types (B- and $\mathrm{B}+$ ) should carry both $A 1$ and $A 2$, whereas the green types $(\mathrm{G}-$ and $\mathrm{G}+$ ) should not carry either. Consequently, $45 \mathrm{~N}$ was determined as $A 1 ; A 2 ; b 1$ (Table 4). When $45 \mathrm{~N} 1$ was crossed with $3 \mathrm{M} 1$, a TS culture with $P W T 1 ; p w t 2$, all progeny cultures showed the $\mathrm{B}+$ type (Table 5), suggesting that $45 \mathrm{~N} 1$ carries $P W T 1$. Here, Al tentatively was designated as $P W T 1$. On the other hand, crosses of 45N1 with TA cultures 61M2 (pwt3;PWT4) and 86Q1 (PWT3; $P W T 4)$ produced virulent $(\mathrm{G}+)$ progeny in ratios of $7: 1$ and $15: 1$, respectively (Table 5), suggesting that $A 2$ is different from $P W T 3$ and PWT4. Therefore, $A 2$ was designated as PWT5.

\section{DISCUSSION}

We have crossed a Triticum isolate (Br48) with a Setaria isolate (GFSI1-7-2) (7), an Avena isolate (Br58) (10), and an Oryza isolate (PO12-7301-2) (this study). Genetic analyses of the progenies made it possible to identify five loci (Pwt1, Pwt2, Pwt3, $P w t 4$, and $P w t 5)$ involved in the specific pathogenicity of those field isolates on wheat. Results of these studies are summarized in Table 6. The Oryza and Setaria isolates share two avirulence genes, PWT1 and PWT2, while the Avena isolate carries other avirulence genes. This is reasonable because Oryza isolates are genetically closer to Setaria isolates than to Avena isolates. For example, the MAGGY retrotransposon (2) is present in multiple copies in Oryza and Setaria isolates (11) but absent in Avena isolates (unpublished data). In the rDNA-ITS2 sequence, Oryza isolates are identical to Setaria isolates but different from Avena isolates (8). The Triticum isolate carries none of the five avirulence genes and, therefore, is virulent on wheat (Table 6).

When pathogenicity of the TO cultures were tested on rice cultivars, all 94 cultures were avirulent (data not shown). The difference of the mode of segregation on wheat and rice may be related to the history of their interaction with $M$. oryzae. Rice has been attacked continuously by $M$. oryzae and had to acquire many resistance genes during the long history of interaction. On the other hand, wheat has been cultivated under a dry condition which is unsuitable for infection with $M$. oryzae, and probably did not have to acquire many resistance genes. It was not until the 1980s that $M$. oryzae caused severe damage to wheat production (12). Wheat may be a "living fossil" from the viewpoint of resistance to M. oryzae.

\section{ACKNOWLEDGMENTS}

This work was supported by a grant from Ministry of Education, Culture, Sports, Science and Technology, the Japanese government (grant 14206006). We thank H. Kato, former professor at Kobe University, for valuable suggestions and comments.

\section{LITERATURE CITED}

1. Couch, B. C., and Kohn, L. M. 2002. A multilocus gene genealogy concordant with host preference indicates segregation of a new species, Magnaporthe oryzae, from M. grisea. Mycologia 94:683-693.

2. Farman, M. L., Tosa, Y., Nitta, N., and Leong, S. A. 1996. MAGGY, a retrotransposon in the genome of the rice blast fungus Magnaporthe grisea. Mol. Gen. Genet. 251:665-674.

3. Heath, M. C. 1981. A generalized concept of host-parasite specificity. Phytopathology 71:1121-1123.

4. Kang, S., Sweigard, J. A., and Valent, B. 1995. The $P W L$ host specificity gene family in the blast fungus Magnaporthe grisea. Mol. Plant-Microbe Interact. 8:939-948.

5. Kato, H., and Yamaguchi, T. 1982. The perfect state of Pyricularia oryzae Cav. from rice plants in culture. Ann. Phytopathol. Soc. Jpn. 48:607-612.

6. Kato, H., Yamamoto, M., Yamaguchi-Ozaki, T., Kadouchi, H., Iwamoto, Y., Nakayashiki, H., Tosa, Y., Mayama, S., and Mori, N. 2000. Pathogenicity, mating ability and DNA restriction fragment length polymorphisms of Pyricularia populations isolated from Gramineae, Bambusideae and Zingiberaceae plants. J. Gen. Plant Pathol. 66:30-47.

7. Murakami, J., Tosa, Y., Kataoka, T., Tomita, R., Kawasaki, J., Chuma, I., Sesumi, Y., Kusaba, M., Nakayashiki, H., and Mayama, S. 2000. Analysis of host species specificity of Magnaporthe grisea toward wheat using a genetic cross between isolates from wheat and foxtail millet. Phytopathology 90:1060-1067.

8. Oh, H. S., Tosa, Y., Takabayashi, N., Nakagawa, S., Tomita, R., Don, L. D., Kusaba, M., Nakayashiki, H., and Mayama, S. 2002. Characterization of an Avena isolate of Magnaporthe grisea and identification of a locus conditioning its specificity on oat. Can. J. Bot. 80:1088-1095.

9. Sweigard, J. A., Carroll, A. M., Kang, S., Farrall, L., Chumley, F. G., and Valent, B. 1995. Identification, cloning, and characterization of $P W L 2$, a gene for host species specificity in the rice blast fungus. Plant Cell 7:1221-1233.

10. Takabayashi, N., Tosa, Y., Oh, H. S., and Mayama, S. 2002. A gene-forgene relationship underlying the species-specific parasitism of Avenal Triticum isolates of Magnaporthe grisea on wheat cultivars. Phytopathology $92: 1182-1188$.

11. Tosa, Y., Nakayashiki, H., Hyodo, H., Mayama, S., Kato, H., and Leong, S. A. 1995. Distribution of retrotransposon MAGGY in Pyricularia species. Ann. Phytopathol. Soc. Jpn. 61:549-554.

12. Urashima, A. S., Igarashi, S., and Kato, H. 1993. Host range, mating type and fertility of Pyricularia grisea from wheat in Brazil. Plant Dis. 77:1211-1216.

13. Valent, B., and Chumley, F. G. 1991. Molecular genetic analysis of the rice blast fungus, Magnaporthe grisea. Annu. Rev. Phytopathol. 29:443-467.

14. Yaegashi, H. 1978. Inheritance of pathogenicity in crosses of Pyricularia isolates from weeping lovegrass and finger millet. Ann. Phytopathol. Soc. Jpn. 44:626-632. 